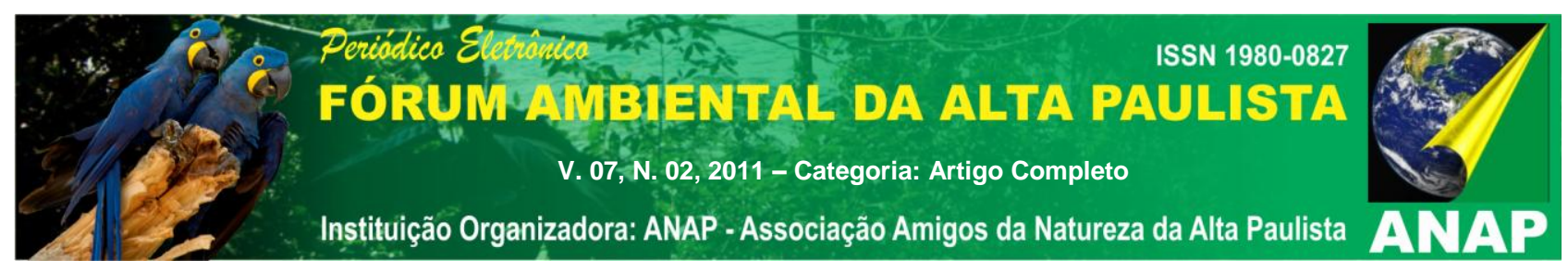

\title{
O PROJETO DE DESENVOLVIMENTO RURAL SUSTENTÁVEL - MICROBACIAS II
}

\author{
Carlos de Castro Neves Neto ${ }^{1}$
}

RESUMO: O artigo visa discutir os programas de microbacias no Estado de São Paulo. Entre 200 - 2008 foi implantado o Programa Estadual de Microbacias Hidrográficas que contou com recursos do Banco Mundial e do Governo do Estado. Essa política pública estadual foi comandada pela CATI e focou no manejo adequado dos recursos naturais e no fortalecimento das Associações de Produtores Rurais. Com o fim do programa em 2008, foi lançado em 2011 o Projeto de Desenvolvimento Rural Sustentável - Microbacias II, que visa à geração de renda entre os produtores familiares que estejam organizados em Associações e/ou Cooperativas.

\section{Introdução}

A alteração da base técnica da agricultura brasileira, consubstanciada no pacote tecnológico da "Revolução Verde" (insumos, máquinas, sementes melhoradas, engenharia genética) e a expansão da frente agrícola em direção a novas áreas a serem exploradas geraram graves danos ambientais, tais como a intensificação dos processos erosivos, o assoreamento dos cursos d'água e a diminuição da fauna e da flora.

No intuito de reverter esse quadro de degradação dos recursos naturais, foram elaboradas políticas públicas que incorporassem a dimensão ambiental na sua operacionalização. Os Estados do Paraná e Santa Catarina foram os pioneiros na formalização dessas políticas e também os primeiros a apresentarem resultados ao adotarem a microbacia hidrográfica como unidade de operação dos programas. Em 1989, - Estado de São Paulo também passou a adotar a microbacia hidrográfica em suas políticas destinadas a agricultura. No entanto, foi a partir de 2000 que o Programa Estadual de Microbacias passou a receber o apoio financeiro do Banco Mundial.

${ }^{1}$ Aluno do Doutorado em Geografia da FCT/UNESP, campus de Presidente Prudente, orientando do Prof.Dr. Antonio Nivaldo Hespanhol e bolsista CAPES. Email: netosulian@gmail.com 


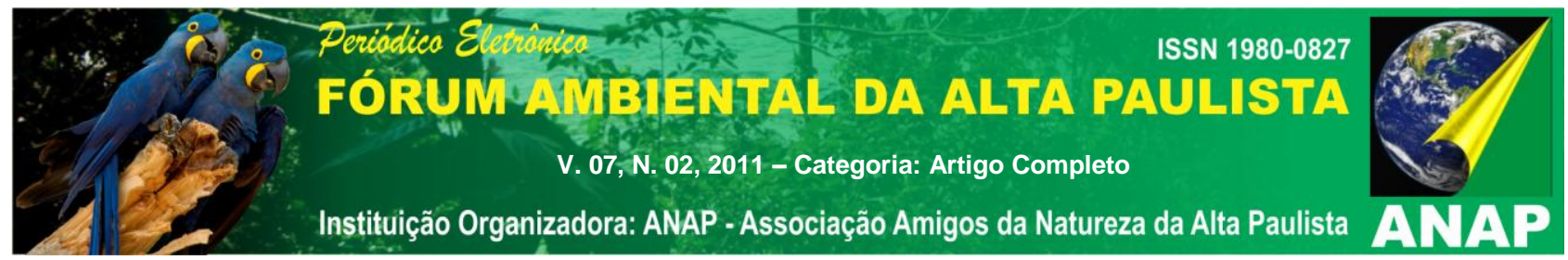

O Programa Estadual de Microbacias Hidrográficas (PEMH), iniciado em 2000, ofereceu uma série de benefícios individuais e coletivos para o produtor rural manejar adequadamente o solo e a água em sua propriedade, sobretudo para os que possuem área de até 50 hectares. Além do Programa de Microbacias, o governo do Estado de São Paulo vem implementando as seguintes políticas públicas em áreas rurais: CATI - Leite Desenvolvendo São Paulo, Sistema Estadual Integrado de Agricultura e Abastecimento (SEIAA), Programa PRÓ - TRATOR, Fundo de Expansão do Agronegócio Paulista Banco do Agronegócio Familiar (FEAP - BANAGRO), Projeto Combate à Erosão, Programa Município Verde, Programa Melhor Caminho, entre outros.

O Programa de Microbacias contou com financiamento do Banco Mundial e busca reverter o quadro de degradação ambiental em que se encontra a maior parte das propriedades rurais no Estado de São Paulo (ZOCCAL, 2007). Para amenizar essa situação, o PEMH ofereceu mudas para o plantio de mata ciliar, cercas para o isolamento das áreas de preservação permanentes, máquina de plantio direto, contratação de horasmáquina para a implantação de terraceamento e implantação de curva de nível. Somado aos benefícios individuais, o PEMH também teve como objetivo fortalecer as associações de produtores rurais (criação da Associação da Federação de Associações de Produtores Rurais de Microbacias Hidrográficas - do Estado de São Paulo - FAMHESP) , com a doação de um kit de informática - composto por computador, impressora, armário, cadeira e mesa - roçadeira, distribuidor de calcário, entre outros equipamentos.

Com o fim do Programa de Microbacias em 2008, foi elaborado o Projeto de Desenvolvimento Rural Sustentável - Microbacias II, que também possui recursos do Banco Mundial e do Governo do Estado de São Paulo, num total de 130 milhões de dólares. O Microbacias II entrou em operação em 2011 e tem duração de cinco anos. Esse novo projeto se difere totalmente do Microbacias I, já que agora esse novo programa vai focar as cadeias produtivas, e não mais as microbacias hidrográficas.

$\mathrm{Na}$ primeira parte do texto, abordaremos o Programa Estadual de Microbacias Hidrográficas em São Paulo, implementado entre 2000 - 2008. Destacaremos os componentes e subcompontentes, as áreas prioritárias e os resultados finais do programa. 


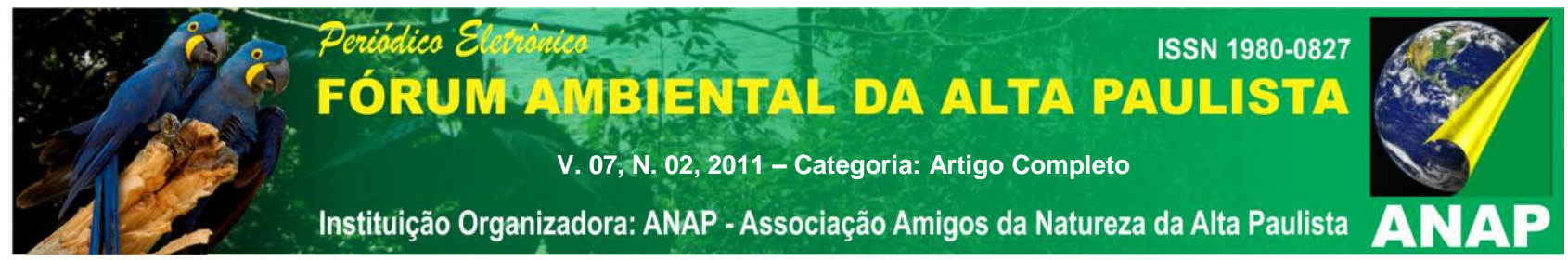

Em seguida, será apresentado o Projeto de Desenvolvimento Rural Sustentável Microbacias II, que ainda está em fase inicial e, portanto, destacaremos as mudanças que ocorreram na elaboração desse novo projeto e as metas estipuladas.

\section{O Programa Estadual de Microbacias Hidrográficas no Estado de São Paulo (2000-2008)}

O Programa Estadual de Microbacias Hidrográficas foi fruto de empréstimo parcial ( $n^{\circ}$. 4238 BR) concedido pelo Banco Mundial ao Governo de São Paulo. O custo total do programa foi estimado em US\$ $124.740 .200,00$, sendo US $\$ 55.348 .000$ financiados pelo Banco Mundial e US\$ 69.342.000,00 contrapartida do governo estadual (CATI, 2001).

O programa foi estruturado em torno de três princípios básicos: sustentabilidade socioeconômica e ambiental na microbacia, participação e envolvimento da sociedade civil, descentralização e transparência nas ações governamentais.

Inspirado no Projeto "Microbacias" (1991-1999) e, principalmente, no "Paraná Rural" (1989-1996), o PEMH entrou em operação em 2000 e caracterizou-se por abranger três princípios básicos: a busca por uma sustentabilidade socioeconômica e ambiental na microbacia (unidade física de intervenção do programa), participação e envolvimento da sociedade civil, descentralização e transparência nas ações governamentais (FONTES, 2006). O PEMH ficou sob responsabilidade da Coordenadoria de Assistência Técnica Integral (CATI), órgão subordinado à Secretaria Estadual da Agricultura e do Abastecimento. Esse programa teve como meta atingir 1500 microbacias hidrográficas, beneficiando 90.000 produtores rurais (30\% do total existente no estado), numa área de 4,5 milhões de hectares, durante o período de 2000 a 2008, já que ele foi prorrogado por mais dois anos. Inicialmente o programa seria concluído no ano de 2006.

A área média de cada microbacia beneficiada pelo PEMH foi de 3.000 hectares, englobando entre 40 a 120 produtores. Os pequenos produtores com área de até 50 hectares e $70 \%$ ou mais da renda da família provendo da agropecuária foram os priorizados para receberem recursos do Programa.

As regiões prioritárias para a ação do programa foram escolhidas com base no grau de degradação ambiental, sobretudo à susceptibilidade à erosão, e os problemas 


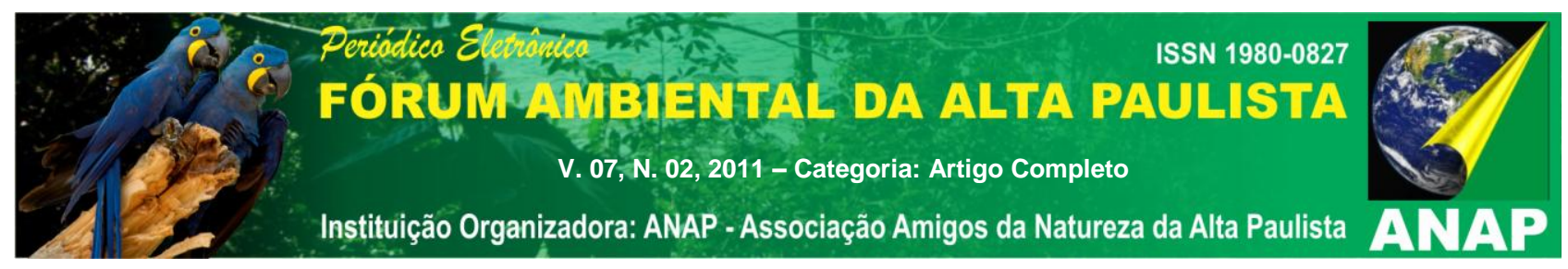

sócio-econômicos dos municípios envolvidos. Para identificar essas áreas, O PEMH utilizou os mapas dos índices de erosão e de indigência do estado de São Paulo, medidos pelo Instituto de Pesquisas Tecnológicas da USP (IPT) e pelo Instituto de Pesquisa Econômica Aplicada

(IPEA).

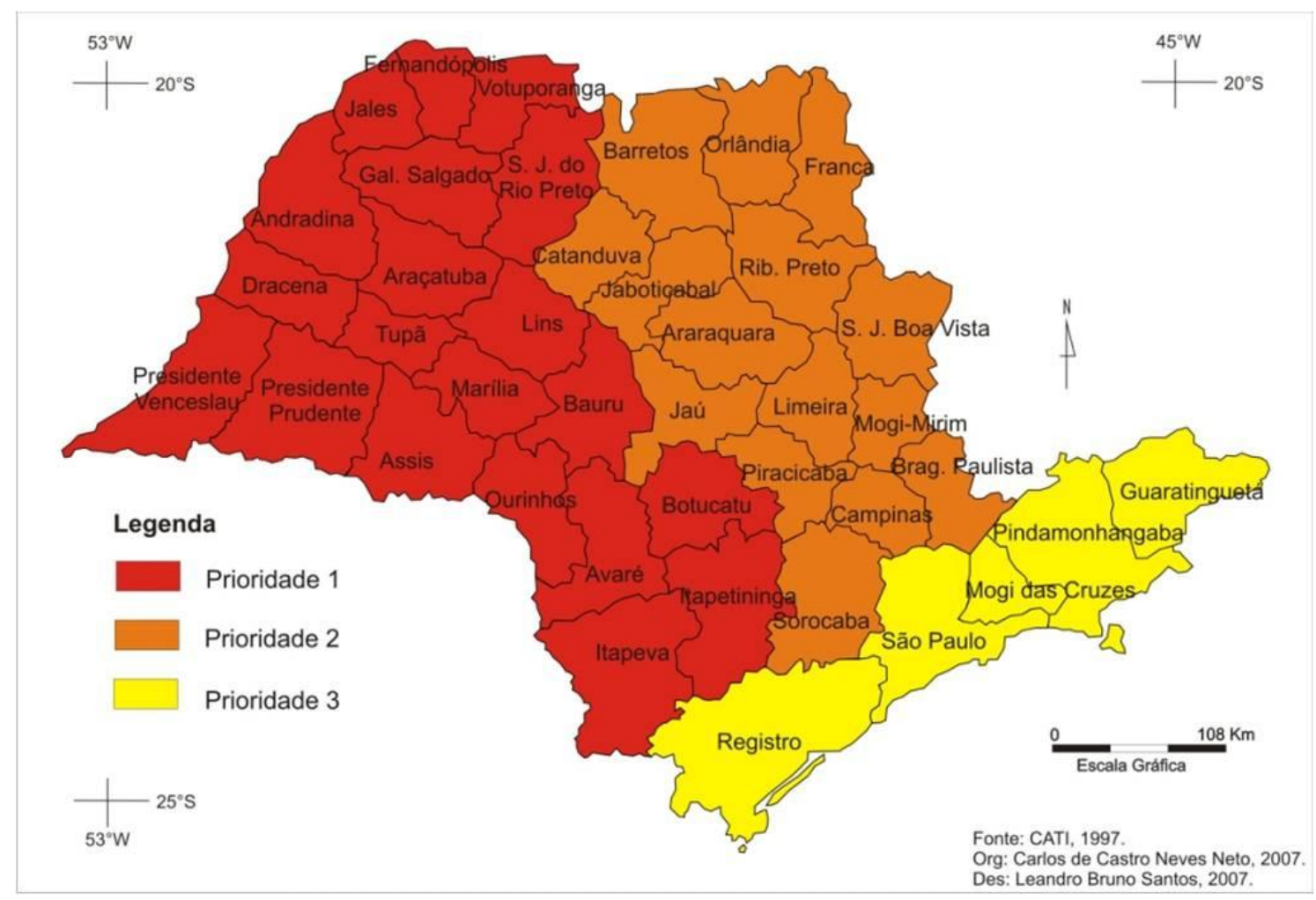

Os recursos financeiros e humanos do $\mathrm{PEMBH}$ destinam-se a três áreas prioritárias. As regiões agrícolas de Andradina, Araçatuba, Assis, Avaré, Bauru, Botucatu, Dracena, General Salgado, Itapetininga, Itapeva, Jales, Lins, Ourinhos, Presidente Prudente, Presidente Venceslau, São José do Rio Preto, Tupã e Votuporanga foram enquadradas na zona prioritária número 1, ficando com $70 \%$ dos recursos. Este privilégio se deve ao forte processo erosivo e o elevado nível de pobreza que estão presentes na maioria dos municípios elencados. A área prioritária número 2 , que recebeu $27 \%$ dos recursos, anvolveu as regiões agrícolas de Araraquara, Barretos, Bragança Paulista, Campinas, Catanduva, Franca, Jaú, Jabuticabal, Limeira, Mogi-Mirim, Olândia, Ribeirão Preto, São João da Boa Vista. Por fim, compõe a zona prioritária número 3, as regiões de Garantiguetá, Mogi das Cruzes, Pindamonhangaba, São Paulo e Registro, disponibilizando de apenas $3 \%$ dos recursos do total. 


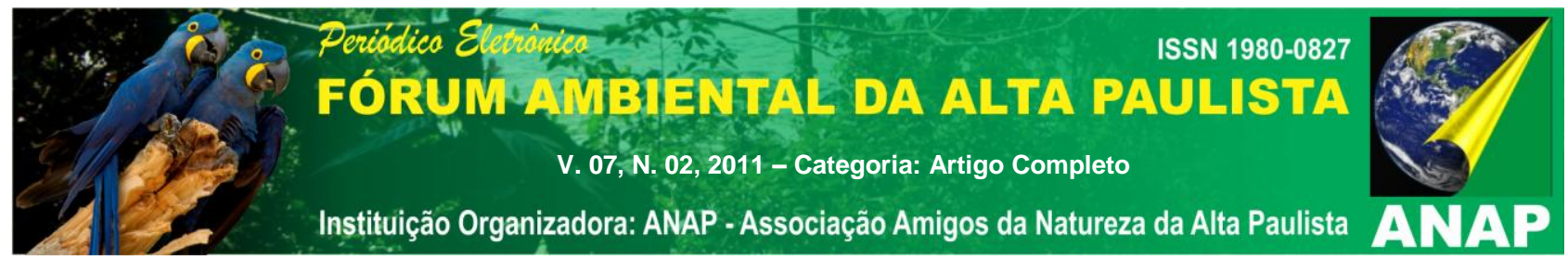

O PEMH foi dividido em seis componentes: Desenvolvimento Tecnológico e Institucional; Pesquisa Adaptativa; Adequação de Estradas Rurais; Treinamento e Difusão; Administração; Monitoramento e Avaliação. Estes se dividem em oito subcompontes: Assistência Técnica e Extensão Rural, Organização Rural; Mapeamento Agroambiental; Educação Ambiental, Incentivo ao Manejo e a Conservação do Solo e Controle de Poluição; Incentivo à Recuperação de áreas degradadas; reflorestamento; Fiscalização da Lei de Uso do Solo e de Incentivo,

Alguns componentes não tiveram uma boa atuação, como os componentes Educação Ambiental e Pesquisa Adaptativa. No primeiro item, não foi cumprida a meta de formação dos Agentes Ambientais e muitas práticas inadequadas ainda se mantém, como a prática da queimada dos resíduos domésticos, como foi constatado em pesquisa de campo no município de Assis.

Já o componente Pesquisa Adaptativa praticamente não funcionou, haja vista que as decisões do Programa de Microbacias se concentraram na Secretaria de Agricultura e Abastecimento, por meio da Coordenadoria de Assistência Técnica Integral - CATI. As Universidades e os Comitês de Bacias Hidrográficas praticamente não foram consultadas na elaboração/implementação do Programa de Microbacias.

No entanto, os componentes Organização Rural e Adequação de Estradas Rurais tiveram sucessos, já que mais de 400 Associações foram criadas e/ou fortalecidas no Estado de São Paulo, e diversos quilômetros de estradas rurais foram readequadas, facilitando o transporte de pessoas e produtos agropecuários.

As principais práticas individuais oferecidas pelo Programa de Microbacias foram: adubação verde, cercas para proteção de mananciais, controle de erosão e de pneu (horas de serviço de trator de esteira), fossa séptica biodigestora e clorador de água, calcário com frete (27 toneladas), sistema de divisão de pastagem (1 kit para cerca elétrica e bebedouro), recuperação de área de preservação permanente (aquisição de mudas e manutenção durante $\circ 1^{\circ}$ ano).

Dentre as práticas coletivas, foram disponibilizados aos produtores abastecedouro comunitário (tipo I e II) ${ }^{2}$, abastecedouro comunitário tipo III, escarificador, distribuidor de

\footnotetext{
${ }^{2}$ Diferença entre os Abastecedouros I, II e III:
} 


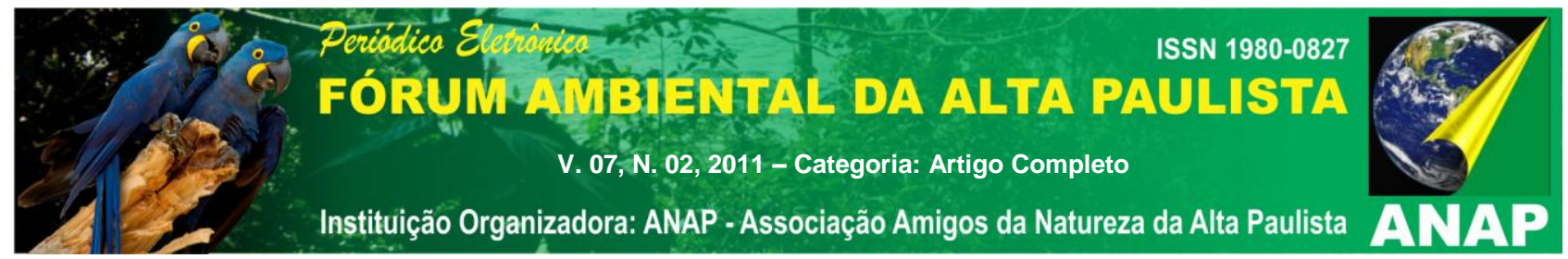

calcário, roçadeira (traçada e tratorizada), semeadora de plantio direto (tração animal) e a roçadeira costal.

Até novembro de 2005, o PEMH tinha aplicado $\mathrm{R} \$ 19,1$ milhões de reais em investimentos diretos para o produtor rural, seja na forma coletiva, seja individual. Em torno de 9,1 mil produtores rurais usufruíram dos recursos do programa. Para o ano de 2006, o programa disponibilizou um montante de recurso para a readequação de estradas rurais em torno de $R \$ 19$ milhões de reais (CATI, 2001).

Conforme Raschliator e Moreira (2006), até o final de 2005, o PEMH não havia gasto todo o recurso disponível, ficando bem longe da expectativa. Do montante previsto para o programa (124.000.000), apenas 31.77\% tinham sido gastos até dezembro de 2005 e até o ano de 2004, somente 17,50\% tinham sido consumidos, conforme o gráfico

Programa Estadual de Microbacias Hidrográficas Evolução do valor apoiado (R\$) aos produtores rurais na forma de Subvençöes Econômicas

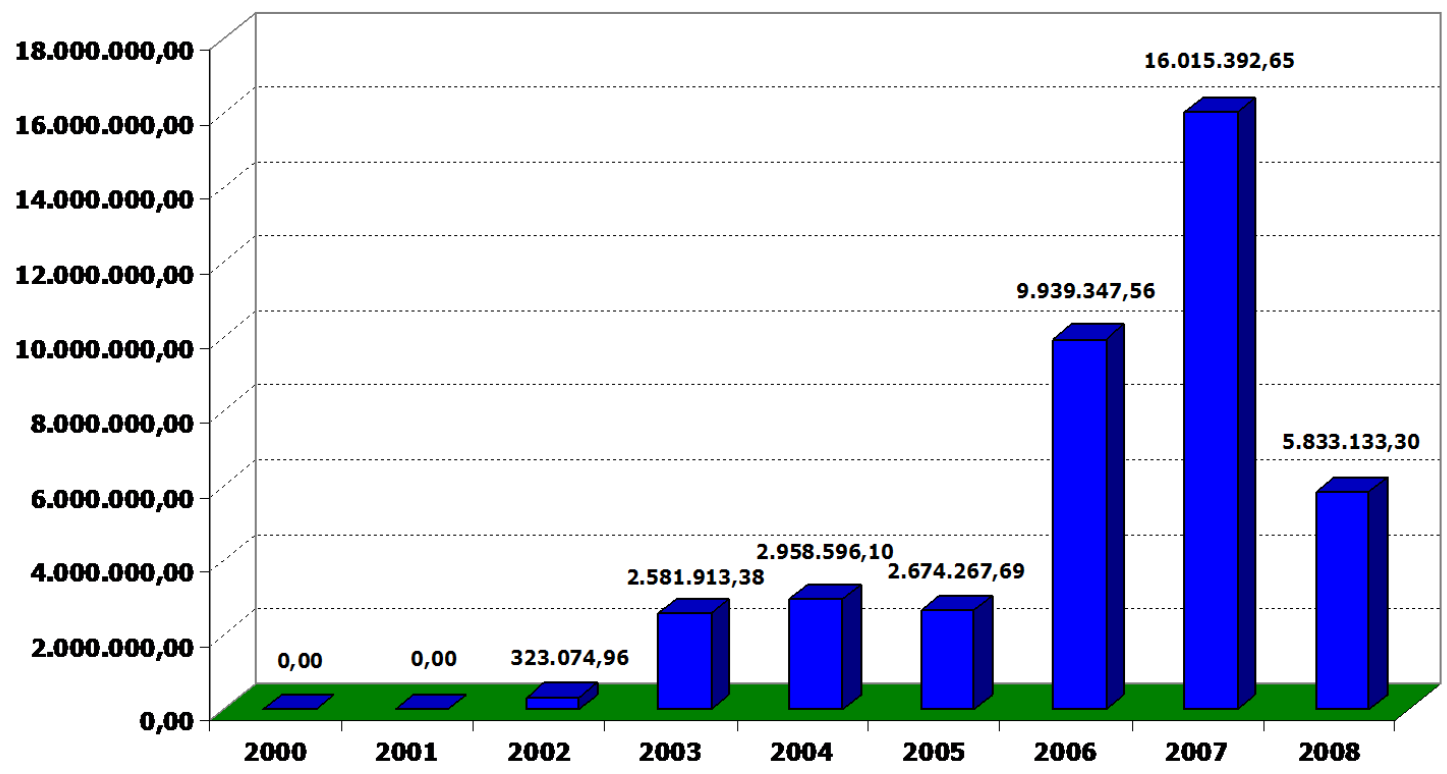

abaixo

Tipo I: abastecedouros cuja captação de água se dá por interceptação de curso d'água ou pela construção de pequena barragem, com condução de água, totalmente por gravidade, até um depósito ou diretamente ao pulverizador;

Tipo II: abastecedouros cuja captação é de água superficial, via bombeamento por moto-bomba, roda d'água, etc., até um reservatório de onde é distribuída para os integrantes do grupo;

Tipo III: abastecedouros cuja captação de água é realizada em poços profundos (poços tubulares profundos), bombeada por moto-bomba até reservatórios elevados de onde é distribuída para os integrantes do grupo (CATI, 2005). 


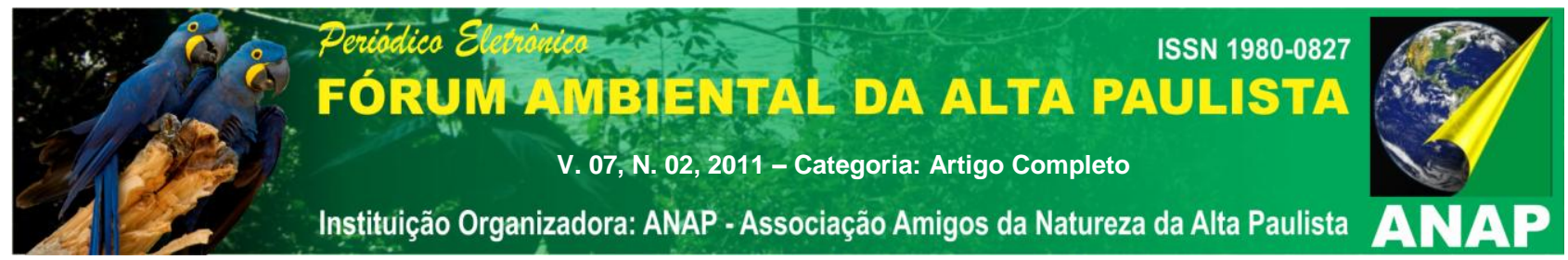

Apesar de o programa ter demorado a "engrenar", ele deslanchou a partir de 2005, já que houve uma expansão de $81,54 \%$ das atividades, em comparação ao total dos anos anteriores. O Diretor do E.D.R. de Assis, Paulo Arlindo, que foi um dos co-autores do $\mathrm{PEMH}$, relatou, em entrevista ${ }^{3}$, que poucas pessoas acreditavam no sucesso do programa nos seus primeiros anos de implantação. Até mesmo os produtores rurais tinham receio que essa nova política de desenvolvimento rural do Estado de São Paulo daria certo. Após alguns proprietários conseguirem vários benefícios (calcário, cercas, terraceamento, abastecedouros entre outros), a notícia se espalhou e outros agricultores das microbacias passaram a confiar nessa política e a buscar seus benefícios (NEVES NETO, 2009).

Para o acesso a benefícios coletivos, cada grupo de produtores rurais, formado por no mínimo cinco produtores, teve que fazer um Projeto de Empreendimento Comunitário PEC e para o acesso ao incentivo por estabelecimento rural foi necessário elaborar um Plano Individual de Propriedade - PIP.

O público alvo do Programa de Microbacias foi as pequenas propriedades rurais, que se definiram segundo tais critérios: Pequeno: Até 50 ha; $70 \%$ ou mais da renda da família provendo da agropecuária e residir na propriedade ou no município onde está localizada a propriedade ou em município vizinho deste; Médio: Entre 50 ha até 200 ha ou área total expandida até 50 ha e que não atende os critérios de fonte de renda e/ou local de residência, necessário para a classificação como pequeno produtor; Grande: Área maior que 200 hectares.

No tocante aos gastos do PEMH (até agosto de 2007) $R \$ 120$ milhões de reais foram investidos, sendo $R \$ 68$ milhões em recuperação de estradas rurais, $R \$ 5,1$ milhões para a compra de kits de informática e máquinas de plantio direto para as associações de pequenos produtores e $R \$ 46,3$ milhões em benefícios individuais ou coletivos $^{4}$.

Devido a grande desvalorização do dólar perante o real nos últimos anos, o Programa Estadual de Microbacias Hidrográficas reajustou em 25\% (08/2007) o teto por beneficiário, passando de US\$ 3.000 para US\$ 3.750 dólares por produtor. Este aumento

\footnotetext{
${ }^{3}$ Entrevista realizada no dia 21/08/2008.

${ }^{4}$ Informações obtidas no site: http://www.saopaulo.sp.gov.br/sis/lenoticia.php?id=86826 Acessado em 20/10/2007.
} 
foi necessário para evitar que os produtores rurais atendidos ficassem desestimulados em adotar as práticas conservacionistas preconizadas ${ }^{5}$.

$\mathrm{O}$ PEMH alcançou resultados positivos entre os produtores rurais do Estado de São Paulo. Conforme Abramovay (2004), este programa valoriza os segmentos mais pobres dos agricultores. Além desse fator, o PEMH descentralizou as ações, antes restritas ao poder executivo; passando a fazer associações com empresas privadas, instituições, universidades; incentivou a criação de Associações de Produtores Rurais, sendo eles, conjuntamente com os Conselhos Municipais de Desenvolvimento Rural, os responsáveis pelos gastos do programa e introduziu na política agrícola de São Paulo, a problemática ambiental, procurando integrar organicamente as condições sociais e ambientais responsáveis pelo desenvolvimento rural.

Por outro lado, a alta rotatividade dos engenheiros agronômicos contratados pelo CATI, devido aos baixos salários, o baixo número de profissionais destinados especificamente ao PEMH (sobretudo agrônomos), a falta de confiança dos produtores rurais nas ações do programa e o número reduzido de parcerias, principalmente com as Universidades, são alguns aspectos negativos na sua operacionalização.

Ainda observamos a influência de interesses político-partidários que dificulta a operacionalização correta do programa. "Na seleção dos municípios beneficiários e das microbacias nem sempre predominam os critérios técnicos, havendo forte ingestão de interesses políticos" (HESPANHOL, p. 13, 2007).

Conforme a tabela abaixo, o Programa de Microbacias atendeu 518 municípíos, num total de 70.400 produtores beneficiados. Foram controladas 830 voçorocas e implantadas 46.525 práticas conservacionistas. No âmbito municipal, o principal item é a recuperação de $1.232 \mathrm{~km}$ de estradas rurais em 300 municípios no Estado de São Paulo.

- Últimos resultados do PEMH - 01/09/2008

\begin{tabular}{|l|l|}
\hline Indicadores & Realizado \\
\hline Municípios envolvidos; & 518 \\
\hline
\end{tabular}

\footnotetext{
${ }^{5}$ Informações obtidas no site: http://www.cati.sp.gov.br/ Cati2007/ projetos/pemh/ValorPraticaApoiadas.php. Acessado em 20/10/2007.
} 


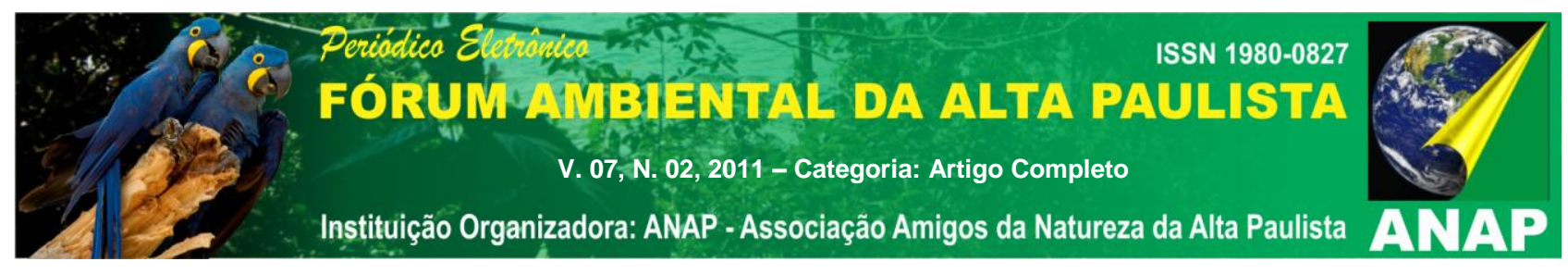

\begin{tabular}{|l|l|}
\hline Produtores beneficiados; & 70.400 \\
\hline Microbacias trabalhadas; & 986 \\
\hline Área total trabalhada (ha); & 3.290 .200 \\
\hline Projetos Individuais de Propriedade - PIP elaborados; & 26.000 \\
\hline Associações de produtores formadas/fortalecidas; & 369 \\
\hline Estradas rurais adequadas em 300 municípios; & $1.232 \mathrm{~km}$ \\
\hline Produtores beneficiados com incentivos diretos; & 16.284 \\
\hline Dinheiro desembolsado em incentivos diretos; & $\mathrm{R} \$ 24,9$ milhões \\
\hline Agentes ambientais capacitados; & 600 \\
\hline Voçorocas controladas em áreas degradadas; & 830 \\
\hline Mudas de espécies nativas produzidas e distribuídas; & 2.500 .000 \\
\hline Mata ciliar recomposta (ha); & 1.300 \\
\hline Cerca de proteção construídas em nascentes ou riachos e & $602 \mathrm{~km}$ \\
\hline Práticas conservacionistas implantadas & 46.525 \\
\hline
\end{tabular}

Fonte: O Programa Estadual de Microbacias Hidrográficas (PEMH): "O Programa de Microbacias melhora a sua vida". Experiências de sucesso. In: CD (room), São Paulo, CATI, 2008. Org. Carlos de Castro Neves Neto.

\section{O Projeto de Desenvolvimento Rural Sustentável - Microbacias II}

Visando aumentar a competitividade da agricultura familiar e, consequentemente, elevar a renda desses agricultores, está sendo lançado o Projeto de Desenvolvimento Rural Susentável, Microbacias II, que novamente terá financiamento do Governo do Estado de São Paulo e do Banco Mundial, sendo o valor total do projeto estimado em US\$130,00, durante cinco anos.

O objetivo geral do Projeto Microbacias II - Acesso ao Mercado é: "aumentar a competitividade da agricultura familiar, no Estado de São Paulo, melhorando simultaneamente a sua sustentabilidade ambiental" (CATI, p.1, 2010). Os Objetivos específicos são:

Aumentar a produtividade e melhoria da qualidade dos produtos através de melhores práticas de produção;

Participar mais ativamente nas cadeias produtivas, onde há uma vantagem comparativa, em função do fortalecimento das parcerias no processamento, comercialização e operações de mercado; 


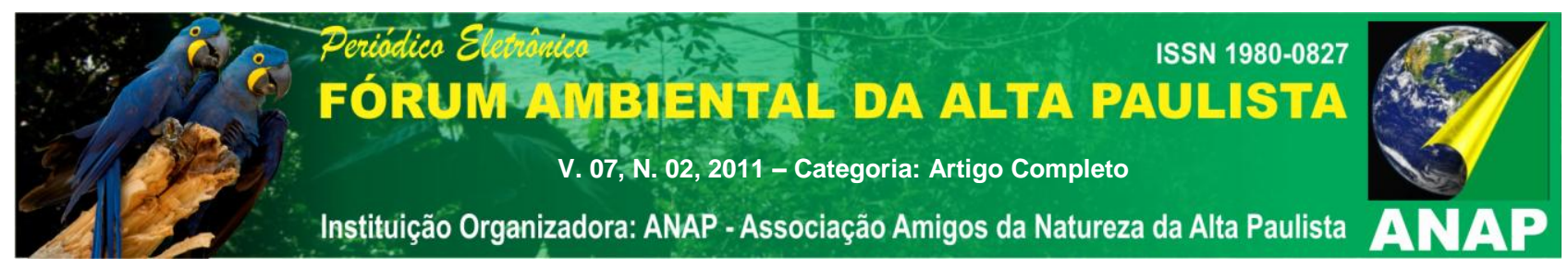

Fortalecer a capacidade organizacional e gerencial das organizações de produtores rurais, bem como promover a formação de novas associações ou cooperativas; e

Integrar melhores práticas de manejo do solo e da água e sistemas de produção mais competitivos e sustentáveis, testados no âmbito do Programa Estadual de Microbacias Hidrográficas - PEMH e Projeto de Recuperação de Matas Ciliares - PRMC. (CATI, p.1, 2010)

O foco desse projeto é fortalecer os agricultores familiares dentro das cadeias produtivas e reforçar sua capacidade de negociação coletiva com os atores do mercado. $\mathrm{Na}$ tabela abaixo podemos comparar os dois programas estaduais, O Programa de Microbacias, que foi executado entre 2000 - 2008 e o Projeto de Desenvolvimento Rural Sustentável - Microbacias II, que será executado entre 2010 - 2014.

\begin{tabular}{|l|l|l|}
\cline { 2 - 3 } \multicolumn{1}{c|}{} & PEMH & MICROBACIAS II \\
\hline Foco & Ambiental & $\begin{array}{l}\text { Aumento da competividade - geração de } \\
\text { emprego e renda }\end{array}$ \\
\hline $\begin{array}{l}\text { Unidade de } \\
\text { trabalho }\end{array}$ & $\begin{array}{l}\text { Microbacia } \\
\text { Hidrográfica }\end{array}$ & $\begin{array}{l}\text { Organização de produtores (Associação, } \\
\text { Cooperativa) }\end{array}$ \\
\hline Beneficiários & $\begin{array}{l}\text { Produtores } \\
\text { individuais } \\
\text { grupos produtores } \\
\text { Associações } \\
\text { fortalecimento }\end{array}$ & $\begin{array}{l}\text { Associação e Cooperativa } \\
\text { Agricultores familiares e grupos de uma } \\
\text { cadeia produtiva comum envolvidos pela } \\
\text { Associação/Cooperativa }\end{array}$ \\
\hline Execução & $\begin{array}{l}\text { Plano da MBH } \\
\text { Plano de Negócio }\end{array}$ \\
\hline
\end{tabular}

Analisando a tabela acima, podemos visualizar várias mudanças do Microbacias II para o Programa de Microbacias. O Microbacias II não terá como foco principal o meio 


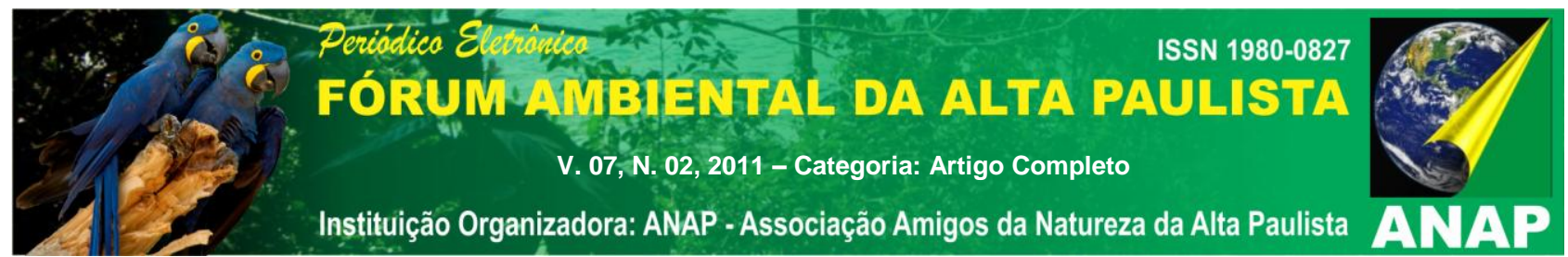

ambiente, mas sim a geração de emprego e renda. Também a unidade operacional foi alterada, passando a ter como foco as organizações de produtores que estão reunidos em Associações e/ou Cooperativas.

Os públicos alvos do Microbacias II serão os agricultores familiares que participarem de uma Associação ou Cooperativa e estiverem envolvidos numa cadeia produtiva comum. Para o acesso aos benefícios, deverá ser elaborado um Plano de Negócio.

Outra mudança interessante foi a definição de agricultura familiar que passa a seguir a Lei 11.326, de 24 de julho de 2006, que inclui pescadores artesanais, comunidades quilombolas e povos indígenas e define esse tipo de agricultor como sendo: Possuem e/ou exploram área agrícola de até 4 módulos fiscais do município;

Obtêm renda familiar predominante da exploração agropecuária e não agropecuária da área explorada; utilizam predominantemente trabalho de suas próprias famílias para a sua produção agrícola e transformação.

Serão atendidos as organizações de produtores rurais (associações ou cooperativas) legalmente constituídas há pelo menos 1 ano, organizações de grupos indígenas e quilombolas, envolvidas em atividades tipicamente rurais agrícolas e não agrícolas.

$\mathrm{Na}$ tabela abaixo podemos visualizar os limites de apoio por organização de agricultores familiares. Como demonstrado, as propostas constituídas por grupo de Associação ou Cooperativas com mais de $70 \%$ de agricultores familiares terá apoio de até $70 \%$.

\begin{tabular}{|l|l|l|l|}
\hline Beneficiários & Caracterização do proponente & $\begin{array}{l}\text { Valor máximo } \\
\text { apoio* }\end{array}$ & $\begin{array}{l}\text { de } \\
\text { apoiado - R\$ }\end{array}$ \\
& & \\
\hline
\end{tabular}




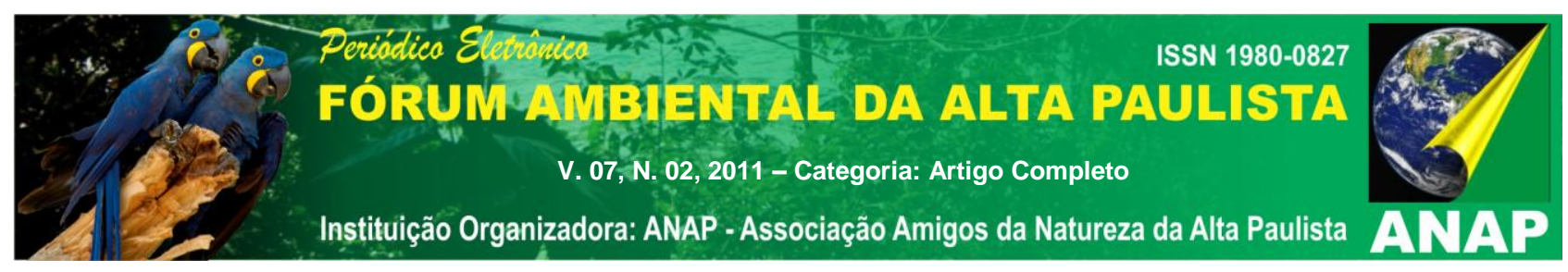

\begin{tabular}{|l|l|l|l|}
\hline & $\begin{array}{l}\text { Proposta constituída por grupo } \\
\text { com mais de } 70 \% \text { de agricultores } \\
\text { familiares }\end{array}$ & Até $70 \%$ & $800.000,00$ \\
$\begin{array}{l}\text { Associações ou } \\
\text { Cooperativas } \\
\text { de produtores } \\
\text { rurais }\end{array}$ & $\begin{array}{l}\text { Proposta constituída por grupo } \\
\text { com mais de 50\% a 70 \% de } \\
\text { agricultores familiares }\end{array}$ & Até 50\% & \\
\hline
\end{tabular}

O Projeto Microbacias II apresenta dois componentes - 1. Apoio às Iniciativas de Negócios dos Agricultores Familiares e 2. Fortalecimento de Instituições públicas e infraestrutura municipal, que se divide e cinco Subcomponentes - 1.1. Investimento em Iniciativas de Negócios dos Agricultores Familiares, 1.2. Fortalecimento das Organizações de Produtores Rurais; 2.1. Políticas Públicas, Monitoramento de Mercado e Extensão Rural, 2.2. Fortalecimento da Infraestrutura Municipal e 2.3. Sustentabilidade Ambiental.

As metas estipuladas pelo Microbacias II estão:

- 300 iniciativas de negócios de associações ou cooperativas financiadas pelo projeto;

- 90\% das Organizações participantes com uma gestão eficaz;

- Centro de informações do Agronegócio on-line em operação;

- 10 Centros Regionais e 150 salas municipais do agronegócio instaladas;

Sistema de pagamento por serviços ambientais implantado;

Sistema de gestão de malha viária municipal implantado em 120 municípios.

Dessa forma, fica nítido que o Projeto de Desenvolvimento Rural Sustentável Microbacias II (2010 - 2014) não tem nenhuma semelhança com o Programa Estadual de Microbacias Hidrográficas (2000 - 2008), apenas mantém o nome. Podemos afirmar que se trata de uma outra política pública que terá como foco principal inserir a agricultura familiar no mercado capitalista.

\section{Considerações Finais}




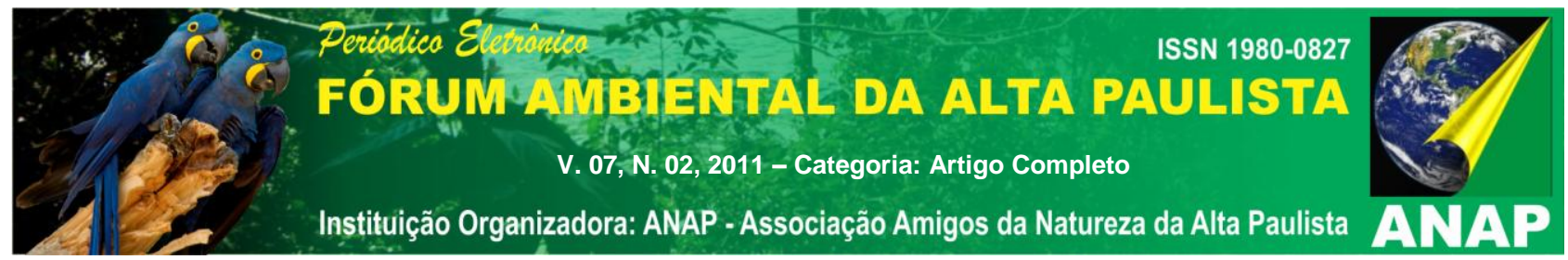

O presente artigo procurou mostrar alguns Programas de Microbacias que ocorreram no Brasil, tendo como foco principal os projetos de Microbacias que ocorreram (em) no Estado de São Paulo.

O Programa Estadual de Microbacias Hidrográficas do Estado de São Paulo, implementado entre 2000 - 2008 teve sucesso nos municípios que contrataram técnicos e agrônomos para a execução do programa. Isso aconteceu, sobretudo, nos Escritórios de Desenvolvimento Rural de Dracena e General Salgado. Em muitos municípios, o programa demorou a ser implementado e sofreu com a falta de recurso material, principalmente, humano.

No entanto, não podemos desconsiderar que o Programa de Microbacias alcançou resultados positivos ao incentivar a formação e/ou fortalecimento de Associações de pequenos Produtores - com a criação da FAMHESP -, apoiou os produtores rurais na cessão de máquinas, na recuperação de erosões e voçorocas, no calcário, na construção de abastecedouros comunitários e na readequação de estradas rurais, facilitando a locomoção de pessoas e de produtos agropecuários.

Em relação ao Projeto de Desenvolvimento Rural Sustentável - Microbacias II, ainda não podemos avaliá-lo totalmente, haja vista que esse programa está numa fase de divulgação, e não possui resultados concretos. Porém, é fácil perceber que o foco ambiental foi deixado de lado, para se priorizar a aspecto econômico. O Microbacias II, como vem sendo chamado, vai priorizar as Associações e/ou Cooperativas que estão consolidadas e formadas há bastante tempo. No entanto, as organizações de produtores que não estiverem fortalecidas e possuírem um número pequeno de produtores - grande parte das Associações no Estado de São Paulo - não conseguirão formular propostas para alcançarem os benefícios oferecidos pelo programa.

Outro problema que poderá acontecer é focar o programa nas cadeias produtivas, o que vai impor à agricultura familiar a produção de um único produto (monocultura), tornando os pequenos agricultores refém das oscilações do mercado. Como defendido por diversos pesquisadores, a agricultura familiar deve produzir diversos produtos, para que possa garantir a segurança alimentar para todos os membros da família e impedir a concorrência desleal do mercado capitalista. 


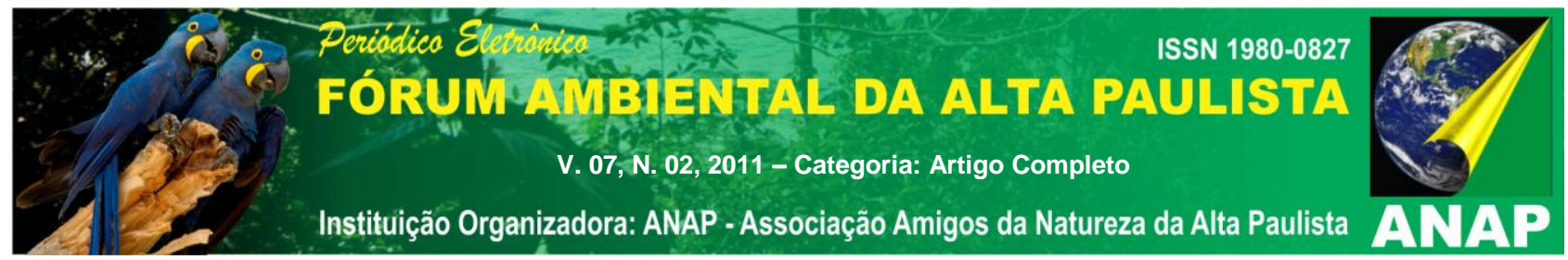

\section{REFERÊNCIAS}

ABRAMOVAY, Ricardo. Organização Rural e Capacitação do Atores. Nota Técnica (relatório final). In: Programa Estadual de Microbacias Hidrográficas São Paulo, 2004.

COORDENADORIA DE ASSISTÊNCIA TÉCNICA INTEGRAL (CATI). Programa Estadual de Microbacias Hidrográficas. Anexos CATI: São Paulo, 2001.

COORDENADORIA DE ASSISTÊNCIA TÉCNICA INTEGRAL (CATI). Programa Estadual de Microbacias Hidrográficas. Manual do Programa - Seção Operativa. CATI: São Paulo, 2001.

COORDENADORIA DE ASSISTÊNCIA TÉCNICA INTEGRAL (CATI). Programa Estadual de Microbacias Hidrográficas. CATI. Seção Operativa- Incentivo ao Manejo e Conservação dos Recursos Naturais, v 3. São Paulo, 2005.

FONTES, José Luiz. Programa de Microbacias Hidrográficas: justificativa, histórico, estratégias e resultados. In: Rodrigues, Valdemir Antonio; BUCCI, Luis Alberto (ORG.). Manejo de microbacias hidrográficas: experiências nacionais e internacionais. Botucatu, FEPAF, 2006, p. 200-215.

HESPANHOL, Antonio Nivaldo. O Desenvolvimento rural na França e no Brasil: as experiências LEADER no centro oeste da Bretanha e do Programa de Microbacias Hidrográficas no Estado de São Paulo. In: V Congresso Europeo CEISAL de latinoamericanistas. Lãs realciones triangulares entre Europa y lãs Américas em el siglo XXI: expectativas y desafios. Bruxelas, 2007.

NEVES NETO, Carlos de Castro. O PROGRAMA ESTADUAL DE MICROBACIAS HIDROGRÁFICAS EM SÃO PAULO: o caso do município de Assis/SP. 196 f. 2009. Dissertação (Mestrado em Geografia). Faculdade de Ciências e Tecnologia, FCT/UNESP, Presidente Prudente.

Secretaria de Agricultura e Abastecimento. Secretaria do Meio Ambiente. Coordenadoria de Assistência Técnica Integral. Coordenadoria da Biodiversidade e dos Recursos Naturais. Projeto de Desenvolvimento Rural Sustentável Microbacias II - Acesso ao Mercado. Manual Operacional, Setembro de 2010.

ZOCCAL, José Cezar. Soluções: cadernos de estudo em conservação do solo e da água. Presidente Prudente: CODASP, 2007. 